\title{
EFFECTS OF A COGNITIVE MODULATOR IN THE THETA AND ALPHA ASYMMETRY DURING A TYPEWRITING TASK
}

\section{A sensorimotor integration perspective}

\author{
Marlo Cunha ${ }^{1,6}$, Sergio Machado ${ }^{1,6}$, Luiz Cláudio Miana3, Dionis Machado ${ }^{7}$, Victor Hugo Bastos ${ }^{1,3,6}$, \\ Bruna Velasques ${ }^{1,6}$, Maurício Cagy ${ }^{2}$, Luis F. Basile ${ }^{5}$, Roberto Piedade ${ }^{1}$, Pedro Ribeiro ${ }^{1,4,6}$
}

\begin{abstract}
This study aimed to elucidate cortical mechanisms and to identify the areas where occur such mechanisms due to interaction between bromazepam and motor learning. The sample was composed of 45 healthy subjects randomly distributed in 3 groups: placebo $(n=15)$, bromazepam $3 \mathrm{mg}(\mathrm{n}=15)$ or bromazepam 6 $\mathrm{mg}(\mathrm{n}=15)$. To perform the experimental task, subjects sat comfortably at a distance of approximately $20 \mathrm{~cm}$ from the typewriter. The typewriter keyboard was covered with a wooden box to avoid visual information about the hands' position. The typewriting task was performed concomitantly with EEG recording. ANOVA two-way results indicated a decreased asymmetry in sensorimotor areas in the experimental groups. Our interpretation is that moderate doses of bromazepam may improve performance on tasks with predictable elements to promote stability of psychomotor functions, but may also impair performance on tasks executed in unpredictable environments.
\end{abstract}

KEY WORDS: bromazepam, motor learning, qEEG, asymmetry, sensorimotor integration.

\section{Efeitos de um modulador cognitivo na assimetria de teta e alfa durante uma tarefa de datilografia: uma perspectiva da integração sensório-motora}

Resumo - O objetivo do estudo foi elucidar mecanismos corticais e identificar as áreas onde estas ocorrem tais mecanismos devido à interação entre bromazepam e aprendizagem motora. A amostra compreendeu 45 sujeitos hígidos distribuídos randomicamente em 3 grupos: placebo ( $n=15)$, bromazepam $3 \mathrm{mg}(\mathrm{n}=15)$ ou bromazepam $6 \mathrm{mg}(\mathrm{n}=15)$. Para a realização da tarefa experimental, sujeitos sentaram-se confortavelmente a uma distância de aproximadamente $20 \mathrm{~cm}$ da máquina de escrever. $O$ teclado da máquina foi coberto com uma caixa de madeira para evitar informações visuais sobre a posição das mãos. O registro do EEGq ocorreu simultaneamente à tarefa de datilografia. Os resultados da ANOVA two-way indicaram menor assimetria em áreas sensório-motoras nos grupos experimentais. Nossa interpretação é que doses moderadas de bromazepam podem melhorar o desempenho em tarefas previsiveis por promover estabilidade das funções psicomotoras, mas pode prejudicar o desempenho em tarefas realizadas em ambientes imprevisiveis.

PALAVRAS-CHAVE: bromazepam, aprendizagem motora, EEGq, assimetria, integração sensório-motora.

\footnotetext{
'Brain Mapping and Sensory Motor Integration, Institute of Psychiatry of the Federal University of Rio de Janeiro (IPUB/UFRJ), Rio de Janeiro RJ, Brazil; ${ }^{2}$ Division of Epidemiology and Biostatistic, Institute of Health Community, Federal Fluminense University (UFF), Rio de Janeiro RJ, Brazil; ${ }^{3}$ Bennett Methodist School, Brazil; ${ }^{4}$ School of Physical Education, Bioscience Department (EEFD/UFRJ), Rio de Janeiro RJ, Brazil; ${ }^{5}$ Division of Neurosurgery, University of São Paulo Medical School, Brazil, Laboratory of Psychophysiology, Faculty of Psychology and Phonoaudiology, UMESP, Brazil; 'B Brazilian Institute of Neural Bioscience (IBBN), Rio de Janeiro RJ, Brazil. Marlo Cunha was supported by CNPq doctoral program grant. Sergio Machado was supported by CAPES doctoral program grant.
}

Received 10 September 2008, received in final form 11 December 2008. Accepted 3 March 2009.

Dr. Marlo Cunha - Rua Antônio Carlos 97 - 24430-090 São Gonçalo RJ - Brasil. E-mail: marlo.marques@bol.com.br 
Bromazepam has been used in an improper manner for different populations. Moreover, there is evidence of a considerable number of prescriptions made by non-psychiatrists'. Considerable positive effects have been shown when bromazepam is used in the treatment of anxiety disorders. However, several experiments have reported conflicting results through tests such as, memory span, critical flicker-frequency, digit symbol substitution, choice reaction time and critical fusion frequency ${ }^{2-6}$. Such conflicts seem to be related to different methodologies performed in a few experiments associated with the effects of bromazepam during specific tasks. Previous results suggest that subjects submitted to acute use of bromazepam suffer impairment in the selection of perceptual-motor response. It may be due to lower capacity of extracting sensory information from environment. In this context, faster responses can be produced; however, these responses are accompanied by a large amount of errors. In these experiments, subjects demonstrated better performance when compared with control on a typewrite task ${ }^{7,8}$. According to our interpretation, such results are mainly due to the nature of the task employed. In contrast to the experiment of Leeuwen et al. ${ }^{6}$, our task requires sustained attention inside on a predictable and a regular perceptual-motor scenario, in other words, it requires a lower demand of decision making based on sensory stimulus. In this sense, our study aimed to elucidate cortical mechanisms and to identify the areas where occur such mechanisms due to interaction between bromazepam and motor learning. Our hypothesis is that lower doses of bromazepam may improve performance on tasks executed in predictable environments due to a possible reduction of sensory information load (e.g., working memory).

\section{METHOD}

\section{Sample}

Sample was composed of 45 healthy subjects ( 23 male and 22 female; aging between 20 to 30 years old), right-handed according to the Edinburgh inventory9. Inclusion criteria were: absence of mental or physical impairments and absence of the use of psychoactive or psychotropic substances (screened by a previous anamnesis and clinical examination). The subjects were instructed to abstain from smoking, taking alcohol, coffee, tea, cola, or any other drinks containing drugs, starting at least $24 \mathrm{~h}$ prior to the experiment day. Subjects with previous experience in typewriting were excluded from the experiment. All participants signed a consent form and were aware of all the experimental protocol. The experiment was approved by the Ethics Committee of Federal University of Rio de Janeiro (IPUB/UFRJ).

\section{Experimental protocol}

The subjects were randomly distributed in 3 groups: placebo ( $\mathrm{n}=15)$, bromazepam $3 \mathrm{mg}(\mathrm{n}=15)$ or bromazepam $6 \mathrm{mg}(\mathrm{n}=15)$.
Therefore, the experiment follows a randomized doble-blind design. The first EEG acquisition was performed before the ingestion of placebo, 3 or $6 \mathrm{mg}$ of bromazepam (i.e., pre task). One hour after the ingestion of placebo or bromazepam, the typewriting task was performed concomitantly with EEG recording. Immediately and thirty minutes after motor task execution, new data were recording (i.e., post task). Finally, a last EEG acquisition was performed in a rest condition (i.e. post task).

\section{Motor task procedures}

The task was performed in a sound and light-attenuated room, to minimize sensory interference. Individuals sat on a comfortable chair to minimize muscular artifacts, while electroencephalography (EEG) was done. To execute the task, subjects sat comfortably at a distance of approximately $20 \mathrm{~cm}$ from the typewriter. The typewriter keyboard was covered with a wooden box to avoid visual information about the hands' position. The task employed followed a typewriting method of progressive learning, in which training was performed on a single day. The task was composed of three blocks, each block represented by twelve lines. Each line had five sequences of letters for each hand. The established sequence of letters for each hand was: asdfg for the left hand, and clkjh for the right hand. When each sequence was over, space key was pressed using the left or right thumb. Individuals were required to employ typewriting movements with maximum velocity and accuracy. The experimental task demanded sustained attention and it was performed in a predictable scenario (i.e., skill closed). The motor behavior results were also published elsewhere ${ }^{7,8,10-12}$.

\section{EEG data acquisition}

The International 10/20 System for electrodes ${ }^{13}$ was used with the 20-channel EEG system Braintech-3000 (EMSA-Medical Instruments, Brazil). The 20 electrodes were arranged in a nylon cap (ElectroCap Inc., Fairfax, VA, USA) yielding monopole derivations referred to linked earlobes. In addition, two 9-mm diameter electrodes were attached above and on the external corner of the right eye, in a bipolar electrode montage, for eyemovement (EOG) artifacts monitoring. Impedance of EEG and EOG electrodes were kept under 5-10 $\mathrm{K} \Omega$. The data acquired had total amplitude of less than $100 \mu \mathrm{V}$. The EEG signal was amplified with a gain of 22,000, analogically filtered between $0.01 \mathrm{~Hz}$ (high-pass) and $100 \mathrm{~Hz}$ (low-pass), and sampled at 240 $\mathrm{Hz}$. The software DataAcquisition (Delphi 5.0), developed at the Brain Mapping and Sensorimotor Integration Laboratory was employed to filter the raw data: notch $(60 \mathrm{~Hz})$, high-pass of $0.3 \mathrm{~Hz}$ and low-pass of $25 \mathrm{~Hz}$.

\section{Data processing and analysis}

To quantify reference-free data, a visual inspection and independent component analysis (ICA) were applied to remove possible sources of artifacts produced by the task. Data from individual electrodes exhibiting loss of contact with the scalp or 
high impedances $(>10 \mathrm{k} \Omega$ ) were deleted and data from single-trial epochs exhibiting excessive movement artifact $( \pm 100 \mu \mathrm{V})$ were also deleted. Independent component analysis (ICA) was then applied to identify and remove any remaining artifacts after the initial visual inspection. ICA is an information maximization algorithm that derives spatial filters by blind source separation of the EEG signals into temporally independent and spatially fixed components. Independent components resembling eye-blink or muscle artifact were removed and the remaining components were then back-projected onto the scalp electrodes by multiplying the input data by the inverse matrix of the spatial filter coefficients derived from ICA using established procedures. The ICA-filtered data were then reinspected for residual artifacts using the same rejection criteria described above. Then, a classic estimator was applied for the power spectral density (PSD), or directly from the square modulus of the FT (Fourier Transform), which was performed by MATLAB 5.3 (Matworks, Inc.). Quantitative EEG parameters were extracted from following moments: before, during (blocks 1, 2 and 3) and after motor task execution. The analyzed electrophysiological variable was theta (4-8 $\mathrm{Hz}$ ) and alpha (8-12 Hz) interhemispheric asymmetry. Asymmetry is defined as the functional difference between the left and right hemispheres; it measures the difference in absolute amplitude which exists between the homologous electrodes located on these hemispheres ${ }^{14}$. It was calculated from the equation: $\mathrm{Pa}-\mathrm{Pb} / \mathrm{Pa}+\mathrm{Pb}$, where $\mathrm{Pa}$ corresponds to the absolute power of the electrode located on the left hemisphere, and $\mathrm{Pb}$ corresponds to the absolute power located on the right hemisphere. These asymmetry data were submitted to statistical analysis.

\section{Statistical analysis}

The qEEG asymmetry data were $\log _{10}$-transformed by SPSS software (version 16.0) to approximate of a normal distribution. Thus, in the statistical analysis, an ANOVA two-way and a Scheffe Post Hoc test were applied to analyze each homologous electrode pair, i.e., F3-F4, F7-F8, C3-C4, T3-T4, T5-T6, P3-P4 and O1-O2 ( $\leq 0.05)$. In this sense, the following factors were analyzed: Condition (Placebo $\times \mathrm{Br} 3 \mathrm{mg} \times \mathrm{Br} 6 \mathrm{mg}$ ) and Blocks $(1 \times 3)$.

\section{RESULTS}

The statistical analysis found a main effect for block and condition factors. In relation to the block main effect, an ANOVA two-way demonstrated a higher negative asymmetry in the alpha band $(p=0.026)$ for the T3T4 electrode pair in the block 3 (mean $=-0.181 \pm 0.06$ ) when compared with block 1 (mean $=-0.035 \pm 0.09$ ). These negative asymmetry values indicate that right electrode (i.e., T4) showed a higher power values when compared with its homologous electrode (i.e., T3), as observed in Figure 1. In relation to the condition main effect, the ANOVA twoway showed three different results in the theta band. In the first analysis, i.e., F7-F8 electrode pair, it was seen a lower positive asymmetry in $\mathrm{Br} 6 \mathrm{mg}$ (mean=0.01 \pm 0.03 )

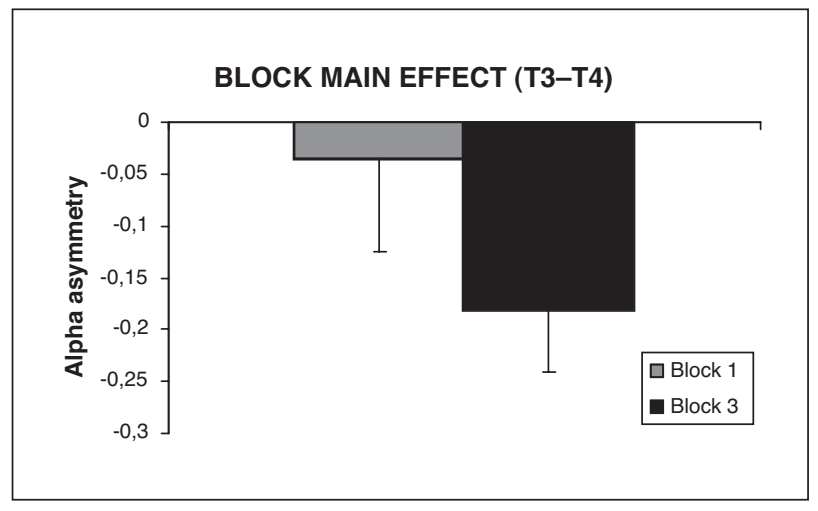

Fig 1. Asymmetry values: significant difference observed between first and last block of the typewriting task $(p=0.026)$.

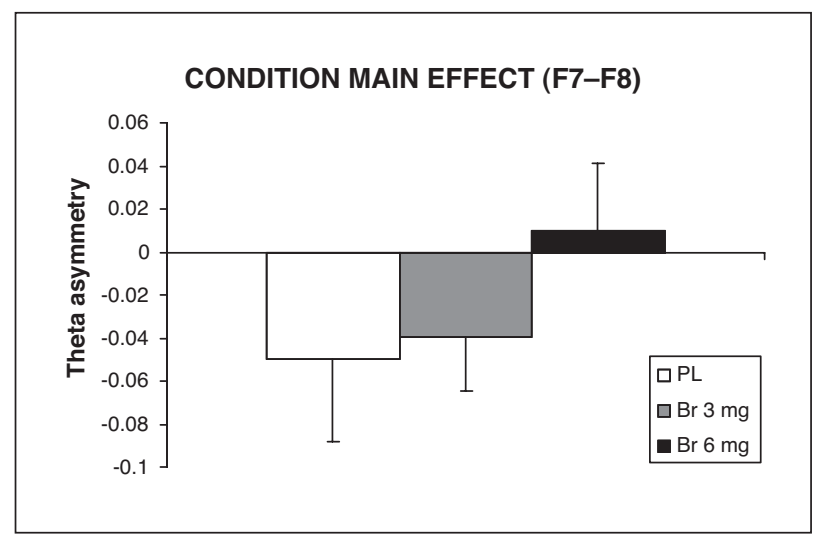

Fig 2. Asymmetry values: significant difference was observed in $\mathrm{Br}$ $6 \mathrm{mg}$ when compared with $\mathrm{Br} 3 \mathrm{mg}$ and $\mathrm{PL}(p=0.029)$.

when compared with $\mathrm{PL}$ (mean $=-0.05 \pm 0.038$ ) and $\mathrm{Br} 3 \mathrm{mg}$ (mean $=-0.04 \pm 0.025$ ) ( $p=0.029)$. Moreover, $\mathrm{Br} 3 \mathrm{mg}$ was not significantly different from PL (Scheffé test). In this manner, such findings can be interpreted as a higher power values in favor of F7 electrode when compared with homologous electrode, i.e., F8 (Fig 2). In the second analysis, i.e., C3-C4 electrode pair, it was found a lower negative asymmetry in $\mathrm{Br} 3 \mathrm{mg}$ (mean= $-0.02 \pm 0.056$ ) and $\mathrm{Br} 6 \mathrm{mg}$ (mean= $-0.01 \pm 0.05)$ were significantly different when compared with PL (mean $=-0.06 \pm 0.076)(p=0.034)$. In addition, $\mathrm{Br} 3$ and $6 \mathrm{mg}$ were not significantly different between them (Scheffé test). Thus, the negative asymmetry observed in all conditions indicates a higher power values in favor of C4 electrode compared with C3 electrode (Fig 3). In the third analysis, i.e., P3-P4 electrode pair, it was observed a lower positive asymmetry in $\mathrm{Br} 6 \mathrm{mg}$ (mean $=0.008 \pm 0.063$ ) when compared with $\mathrm{PL}$ (mean $=-0.05 \pm 0.081$ ) and $\mathrm{Br} 3$ $\mathrm{mg}$ (mean $=-0.03 \pm 0.076)(\mathrm{p}=0.018)$. Moreover, $\mathrm{Br} 3 \mathrm{mg}$ was not significantly different from PL (Scheffé test). Again, $\mathrm{Br} 6 \mathrm{mg}$ in contrast to $\mathrm{Br} 3 \mathrm{mg}$ and PL demonstrated a positive asymmetry, which indicates a higher power values in favor of $\mathrm{P} 3$ electrode when compared with its homologous electrode (i.e., P4), as observed in Figure 4. 


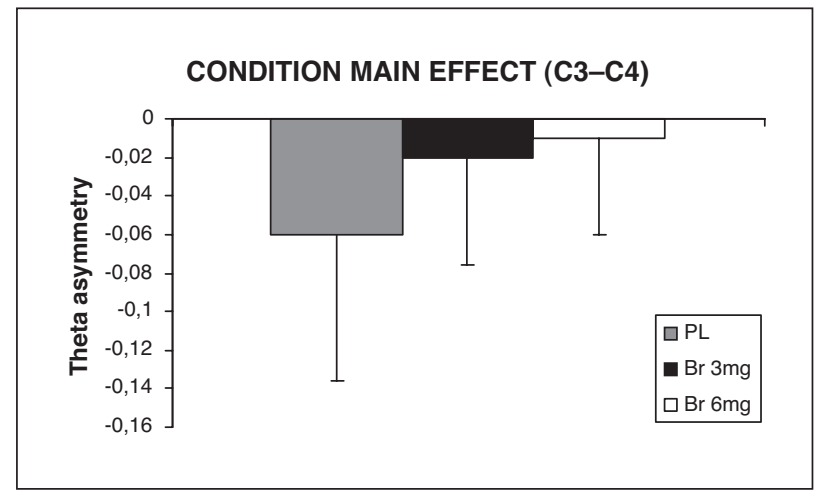

Fig 3. Asymmetry values: significant difference was observed in $\mathrm{Br}$ $3 \mathrm{mg}$ and $\mathrm{Br} 6 \mathrm{mg}$ when compared with $\mathrm{PL}(p=0.034)$.

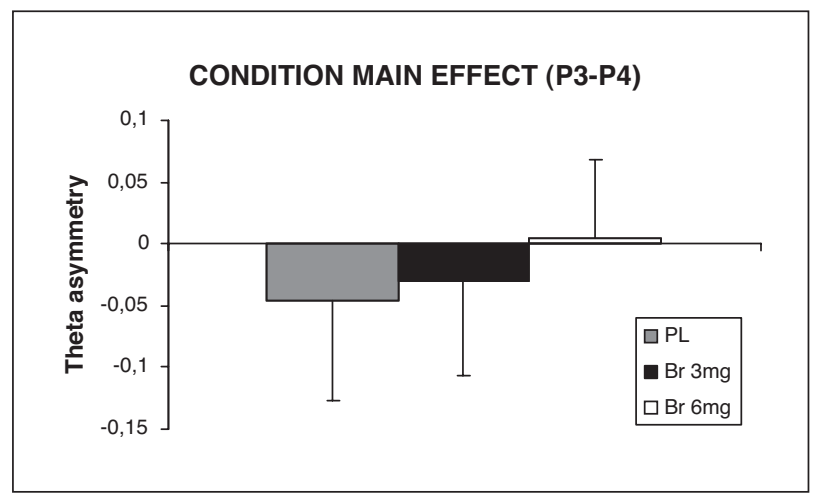

Fig 4. Asymmetry values: significant difference was observed in $\mathrm{Br}$ $6 \mathrm{mg}$ when compared with $\mathrm{Br} 3 \mathrm{mg}$ and $\mathrm{PL}(p=0.018)$.

\section{DISCUSSION}

Our study aimed to elucidate cortical mechanisms and to identify the areas where occur such mechanisms due to interaction between bromazepam and motor learning. Our hypothesis is that lower doses of bromazepam may improve performance on tasks executed in a predictable environment due to a possible reduction of sensory information load (e.g., working memory) requires from individuals when exposed to such tasks.

\section{Changes in alpha asymmetry $(8-12 \mathrm{~Hz})$}

In relation to alpha asymmetry, the block main effect observed on the T3-T4 electrode pair indicates a particular involvement of this region (i.e., temporal cortex), more specifically, near the superior temporal sulci. It suggests a short-term acquisition of a new motor pattern related to the typewriting task. Previous studies reported this region as a multisensory integration center ${ }^{15}$. Despite the sensorimotor features of the task, in the training early phase the subjects possibly used secondary cues such as, the visual information from typewrite (e.g., letters on the paper) and the sound emitted by pressing of each key. The higher negative asymmetry observed in the block 3 when compared to block 1 suggests a specialization due to motor learning process. Such findings can possibly to elucidate functional particularities of the T3 electrode reactivity in the left temporal cortex when compare with your homologous electrode (i.e., T4). According to previous reports the inverse relationship between amplitude and activation level of specific cortical areas ${ }^{16}$, it can be interpreted as a higher activation in the left temporal area (i.e., T3 electrode) when compared with homologous right region (i.e., T4 electrode). As the experimental task was performed bimanually, it suggests a predominance of the left temporal area due to right-handed subjects. Actually, the left hemisphere predominance for motor functions is suggested by other experiments ${ }^{17}$.

\section{Changes in theta asymmetry $(4-8 \mathrm{~Hz})$}

In relation to theta asymmetry, the main effect observed on the F7-F8 electrode pair indicates that only $\mathrm{Br}$ $6 \mathrm{mg}$ condition promotes changes in EEG activity (lower positive asymmetry) when compared with PL. The F7 and F8 electrodes are located near the prefrontal cortex, which is activated when aspects related to planning, judgment and operational memory ${ }^{18}$. Besides, a functional difference in relation to left prefrontal region suggests that it would be more involved in motor functions and right prefrontal region would be more involved in spatial organization functions ${ }^{19}$. In this point of view, it may be suggested that the lower positive asymmetry in $\mathrm{Br} 6 \mathrm{mg}$ reflects a wider balance of electrocortical energy among motor and spatial components of the motor planning. Such fact may be possibly related to a lesser load of information organized in the operational memory, which may be related to an improvement in the typewriting performance due to its execution on a stable motor scenario.

The main effect observed on the $\mathrm{C} 3-\mathrm{C} 4$ electrode pair indicated lower negative asymmetry in $\mathrm{Br} 3 \mathrm{mg}$ and $\mathrm{Br} 6$ $\mathrm{mg}$ when compared with PL. There are several interpretations related to the meaning of theta activity, depending on type of experimental task and involved cortical region. In this manner, the most appropriate interpretation to our findings is that theta activity plays a role of a basic mechanism of information transmission among cortical areas ${ }^{20,21}$. The C3-C4 electrode pair is located near the primary somatomotor cortex, a region functionally related to sensorimotor representations of several body parts ${ }^{22}$. Additionally, there are studies that report the involvement of this region not only in limb's motor command, but also related to motor programming ${ }^{23}$. In this sense, our results on the $\mathrm{C} 3-\mathrm{C} 4$ electrode pair may indicate a differentiated transition between intention and execution in $\mathrm{Br} 3 \mathrm{mg}$ e $\mathrm{Br} 6 \mathrm{mg}$ when compared with placebo. In addition, this drug's effect appeared to facilitate a specific functional integration between the two brain hemispheres. 
In relation to last main effect observed, i.e., on the P3-P4 electrode pair, the findings demonstrated a lower positive asymmetry in $\mathrm{Br} 6 \mathrm{mg}$ when compared with $\mathrm{Br} 3 \mathrm{mg}$ and PL. These electrodes are located over the parietal cortex, which is functionally related to sensorimotor orientation, motor preparation and objects manipulation. Our interpretation is that in this region proprioceptive information (e.g., hand and finger's position on keyboard) and other essential sensory information are joined to assist motor planning ${ }^{24,25}$. The lower positive asymmetry observed, more specially, in the $\mathrm{Br} 6 \mathrm{mg}$, supports the report of Hobi et al. ${ }^{2}$, when it was observed a higher stabilization of the psychomotor performance due to bromazepam effects. Our results suggest that such experimental condition provide a higher functional integration between the left and right cerebral hemispheres, particularly, among sensorimotor areas that compose a parietofronto-central loop. In this manner, the drug's effect over the motor learning seem to influence the performance of this cortical circuit, since the acquisition and integration of sensory stimulus, until the development of a motor behavior based on the same stimulus.

\section{REFERENCES}

1. Alvarenga JM, Loyola Filho AI, Firmo JO, Lima-Costa MF, Uchoa E. Prevalence and sociodemographic characteristics associated with benzodiazepines use among community dwelling older adults: the Bambuí Health and Aging Study (BHAS). Rev Bras Psiquiatr 2008;30:7-11.

2. Hobi V, Dubach U, Skreta M, Forgo I, Riggenddach H. The effect of bromazepam on psicomotor activity and subject mood. J Int Med Res 1981;9:89-96.

3. Hobi V, Dubach UC, Skreta M, Forgo I, Riggenbach H. The subacute effect of bromazepam on psychomotor activity and subjective mood. J Intern Med Res 1982;10:140-146.

4. Jansen A, Verbaten M, Slangen J. Acute effects of bromazepam on signal detection performance, digit symbol substitution test and smooth pursuit eye movements. Neuropsychobiology 1988;20:91-95.

5. Bourin M, Auget JL, Colombel MC, Larousse C. Effects of single oral doses of bromazepam, buspirone and clobazam on performance tasks and memory. Pharmacopsychiatry 1989;22:141-145.

6. Leeuwen Van TH, Verbaten MN, Koelega HS, Kenemans JL, Slangen JL. Effects of bromazepam on single-trial event-related potentials in a visual vigilant task. Psychopharmacology 1992;106:555-564.

7. Cunha M, Machado D, Bastos V, et al. Neuromodulatory effect of bromazepam on motor learning: an electroencephalographic approach. Neurosci Lett 2006;407:166-170.

8. Salles JI, Bastos VH, Cunha M, et al. Neuromodulatory effects of bromazepam when individuals were exposed to a motor learning task: quantitative electroencephalography (qEEG). Arq Neuropsiquiatr 2006;64:112-117.

9. Oldfield R. The assessment and analysis of handedness: the Edinburgh inventory. Neuropsycology 1971;9:97-113.

10. Bastos VH, Machado D, Cunha M, et al. Electroencephalography measures in motor skill learning and effects of bromazepam. Arq Neuropsiquiatr 2005;63:443-451.

11. Machado D, Bastos VH, Cunha M, et al. Effects of bromazepam in qEEG by type writing. Arq Neuropsiquiatr 2005;63:452-458.

12. Cunha $\mathrm{M}$, Bastos $\mathrm{VH}$, Veiga $\mathrm{H}$, et al. Changes in cortical power distribution produced by memory consolidation as a function of a typewriting skill. Arq Neuropsiquiatr 2004;62:662-668

13. Jasper $H$. The ten-twenty electrode system of the international federation. EEG Clin Neurophysiol 1958;10:371-375.

14. Miller A, Tomarken AJ. Task-dependent changes in frontal brain asymmetry: effects of incentive cues, outcome expectancies, and motor responses. Psychophysiology 2001;38:500-511.

15. Beauchamp MS, Yasar NE, Frye RE, Ro T. Touch, sound and vision in human superior temporal sulcus. Neuroimage 2008;41:1011-1120.

16. Palva S, Palva M. New vistas for alpha-frequency band oscillations. Trends Neurosci 2007;30:150-158.

17. Serrien DJ, Ivry RB, Swinnen SP. Dynamics of hemispheric specialization and integration in the context of motor control. Nat Rev Neurosci 2006;7:160-166.

18. Ghilardi M, Ghez C, Dhawan V, et al. Patterns of regional brain activation associated with different forms of motor learning. Brain Res 2000;871:127-145.

19. Garavan H, Ross TJ, Stein EA. Right hemisphere dominance of inhibitory control: an event-related functional MRI study. Proc Natl Acad Sci USA 1999;96:8301-8306.

20. Lopes da Silva FH. Neural mechanisms underlying brain waves: from neural membranes to networks. Electroencephalogr Clin Neurophysiol 1991;79:81-93.

21. Kerick SE, Hatfield BD, Allender LE. Event-related cortical dynamics of soldiers during shooting as a function of varied task demand. Aviat Space Environ Med 2007;78:153-164.

22. Neuper C, Pfurtscheller G. Event-related dynamics of cortical rhythms: frequency-specific features and functional correlates. Int J Psychophysiol 2001;43:41-58.

23. Szurhaj W, Derambure P, Labyt E, et al. Basic mechanisms of central rhythms reactivity to preparation and execution of a voluntary movement: a stereoelectroencephalographic study. Clin Neurophysiol 2003;114:107-119.

24. Mesulam M. Spatial attention and neglect: parietal, frontal and cingulate contributions to the mental representation and attentional targeting of salient extrapersonal events. Phil Trans R Soc Lond B Sci 1999;354:1325-1346.

25. Beurze S, de Lange F, Toni I, et al. Integration of target and effector information in the human brain during reach planning. J Neurophysiol 2007;97:188-199. 